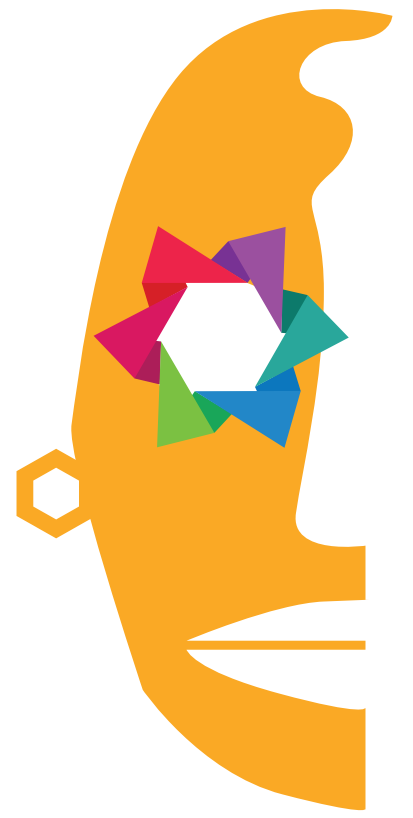

\section{Esteban Alfredo}

Calvo Campos

Escuela Casa del Artista Olga Espinach Fernández
Las huellas de un maestro: Breve comentario a la vida y obra de Rudy Espinoza (1953-2018)

\section{Resumen}

Breve biografía y comentarios de algunas de las obras ${ }^{1}$ más significativas del grabador costarricense Rudy Espinoza (1953-2018), quien durante los últimos diez años de vida, amplió su legado como docente y formador a través del "Taller Nacional de Grabado" de la Escuela Casa del Artista, un espacio alternativo para la enseñanza y aprendizaje de las diferentes técnicas del grabado en todos sus aspectos.

\section{Palabras clave:}

Rudy Espinoza (1953-2018), Grabado en metal, Arte costarricense, Escuela Casa del Artista

\begin{abstract}
:
Brief biography and comments of some of the most significant works of the Costa Rican engraver Rudy Espinoza (1953-2018), who during the last ten years of life, extended his legacy as a teacher and trainer through the "National Workshop of Engraving" of the School Casa del Artista, an alternative space for teaching and learning the different techniques of engraving in all its aspects.
\end{abstract}

Keywords:

Rudy Espinoza (1953-2018), Metal engraving, Costa Rican art, School Casa del Artista

1 Se agradece a la Sra. Rosy Severino, viuda del artista Rudy Espinoza, quien autorizó la reproducción de las obras que ilustran este artículo. 


\section{Cuatro décadas dedicadas al grabado en metal}

Con la energía y vitalidad de un joven veinteañero, el grabador costarricense Rudy Espinoza Morales (1953-2018) se enfrentó a la producción de un ambicioso proyecto expositivo con el cual celebrar su decimocuarto aniversario de trabajo creativo. La muestra que concibió fue titulada sin mayores pretensiones como: "Cuarenta años de grabado en metal 1976-2016". Se trató de una exhibición retrospectiva que engalanó por tres meses las salas Manuel de la Cruz González del Museo Histórico Calderón Guardia, en San José de Costa Rica.

El artista presentó, en esa oportunidad, un conjunto de 81 obras de pequeño y mediano formato, desarrolladas todas a partir de un especial interés por alcanzar el perfeccionamiento de la técnica del grabado en metal, sus múltiples variables y procesos experimentales.

El trabajo de curaduría y selección de obras para dicha exhibición, significó una labor de ordenamiento de sus trabajos de forma cronológica e identificar las piezas que pertenecían a series mayores, de igual manera, se realizó labores de fotografía e inventario de su producción completa. El equipo de esta muestra estuvo integrado por el historiador del arte costarricense Luis Núñez B., quien junto a mi persona desarrollamos la curaduría, la selección de las piezas y el diseño de la museografia; por su parte el equipo de fotografía fue liderado por Alex Arias y asistido por Flavia Sánchez. Hoy, a dos años de distancia de este trabajo, nos percatamos que lo logrado en esa oportunidad trascendió la exhibición, porque gracias a ello contamos con un inventario bastante preciso de toda su producción, lo que nos permitirá ir poco a poco analizando a profundidad su vasto y rico legado.

\section{Esbozo biográfico y breves comentarios a algunas de sus obras}

Rudy Espinoza era licenciado en Artes Plásticas con especialidad en Pintura por la Universidad de Costa Rica (UCR) desde 1975. Durante su estancia en este centro de estudios, el profesor Juan Luis Rodríguez Sibaja (artista grabador costarricense nacido en 1934) quien pocos años antes había regresado a Costa Rica después de concluir sus estudios en Francia y Holanda, le motivó a que experimentara en el taller de grabado en metal de la UCR recién inaugurado. Mediante una comunicación oral en su taller (como parte del trabajo de curaduría de la exposición retrospectiva del 2016), Espinoza nos comparte que en el año 1973 Rodríguez Sibaja se dirigió a él y le dijo: "Si usted viene aquí y entra, [refiriéndose al taller] nunca saldrá"; $y$ así fue, porque esas palabras se convirtieron en una especie de sentencia de vida para el artista.

A partir de ese momento, Espinoza decide orientar sus esfuerzos en el campo del grabado sobre metal por dos razones fundamentales: la primera, vio la 
posibilidad de divulgación de la obra en términos de compartir el producto por medio de la edición, y la segunda, por una afinidad entre sus proposiciones estéticas, los materiales y técnicas que éste le ofrecía. (Durán, 2014, p. 25)

\section{Figura 1. La cuesta (1976)}

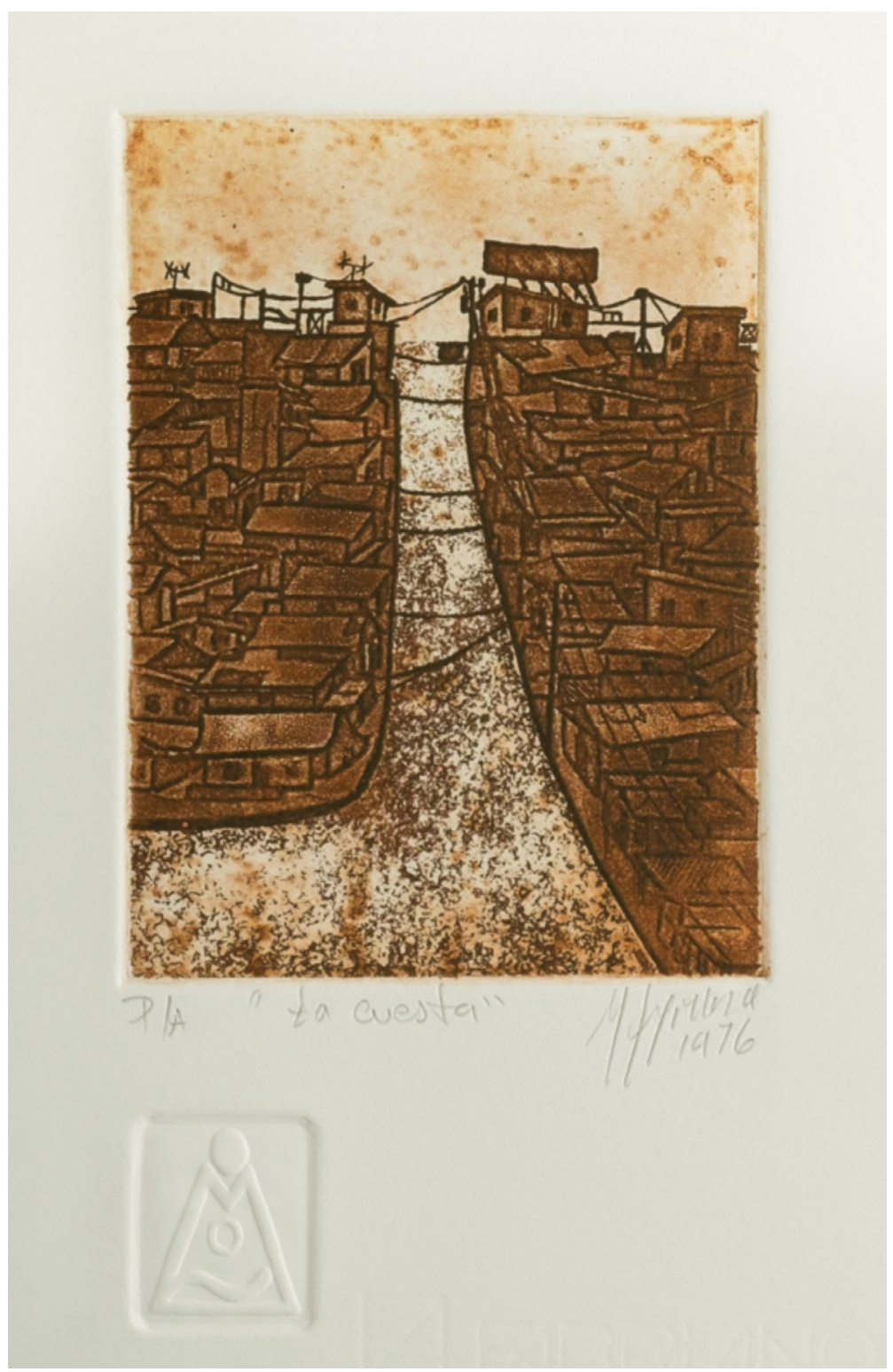

Fuente: Familia de Rudy Espinoza. 
Desde su primera estampa titulada La cuesta (Figura 1.), un aguafuerte de 1976 hasta finales del 2017, Espinoza llegó a producir un corpus de más de 250 estampas en metal, de las cuales cerca de 220 están debidamente editadas y cuidadosamente fotografiadas, lo que se traduce en cientos de estampas y una innumerable cantidad de horas de trabajo en el taller.

A partir de 1978 el taller de la UCR se vio mejorado, ya que se convirtió en la sede del Centro Regional de las Artes Gráficas (CREAGRAF), una iniciativa de la Organización de Estados Americanos (OEA), donde esta organización auspiciaba talleres de grabado orientados a artistas de Centroamérica, el Caribe, Colombia y Venezuela, con la instrucción de maestros grabadores internacionales conocedores del grabado en metal, xilografía, litografía, intaglio, fotograbado, entre otras especialidades. Los artistas latinoamericanos que participaban como estudiantes se seleccionaban por medio de concurso. Espinoza participó en varios de estos cursos donde tuvo la oportunidad de conocer gran cantidad de personalidades de las artes latinoamericanas e internacionales y de esta forma inició una nueva etapa de intercambio de conocimientos y práctica de la técnica (Alvarado, 1992).

Para inicios de la década de los ' 80 , Espinoza ya se desempeñaba como docente del Taller de Grabado de la Escuela de Artes Plásticas de la Universidad Nacional de Costa Rica (UNA) y fue desde este centro educativo que realizó las gestiones para optar por una beca del Programa Fulbright/Laspau Scholarship. Esto le permitió ingresar a la Universidad de Minnesota en donde obtiene, en 1985, el Máster en Artes Plásticas con especialidad en Grabado.

Durante esta estancia de estudios conoce el trabajo y la obra del reconocido artista y grabador inglés Stanley William Hayter (1901-1988) quien había sido el fundador del prestigioso taller de grabado parisino Atelier 17, donde Rodríguez Sibaja había cursado parte de sus estudios. Hayter había desarrollado una novedosa técnica de impresión conocida como "método de impresión Hayter", o "viscosidad de tintas y quemados sucesivos", la cual se fundamenta en la impresión o estampación de una matriz de cobre o zinc grabada en relieve con distintos niveles, mediante la técnica de quemados sucesivos, que había sido entintada con tintas de diferentes viscosidades en superposición, aplicadas con rodillos de gelatina de diferentes densidades (Hayter, 1981, pp. 140-153). Con este complejo y experimental procedimiento técnico se obtienen impresiones de gran variedad cromática a partir de una sola matriz, lo que para Espinoza y su extraordinario sentido del color, fue una verdadera revelación y de inmediato se abocó en estudiar la técnica para incluirla dentro de su repertorio. 
Figura 2. Mario (1992)

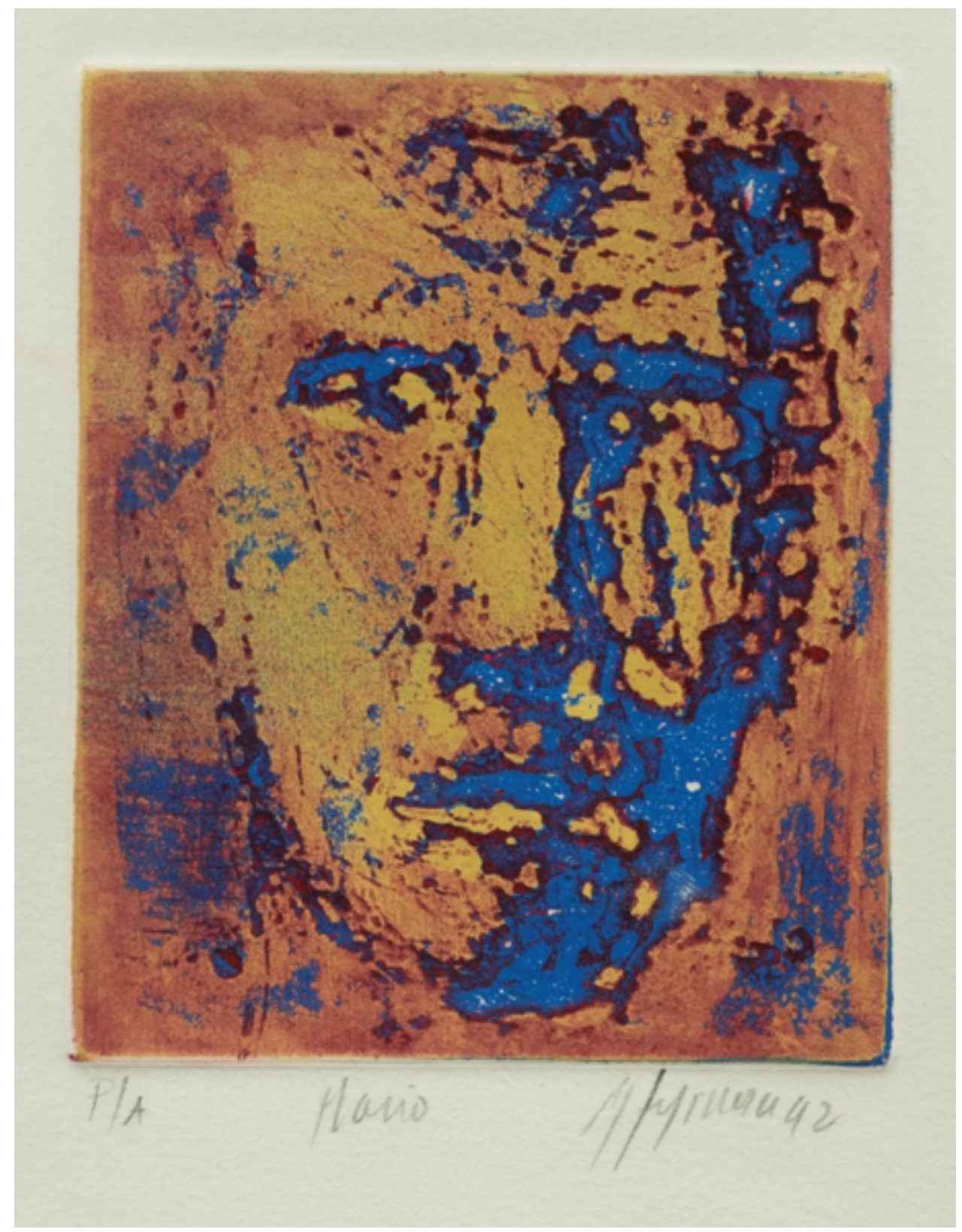

Fuente: Familia de Rudy Espinoza 
Figura 3. Mario (1992)

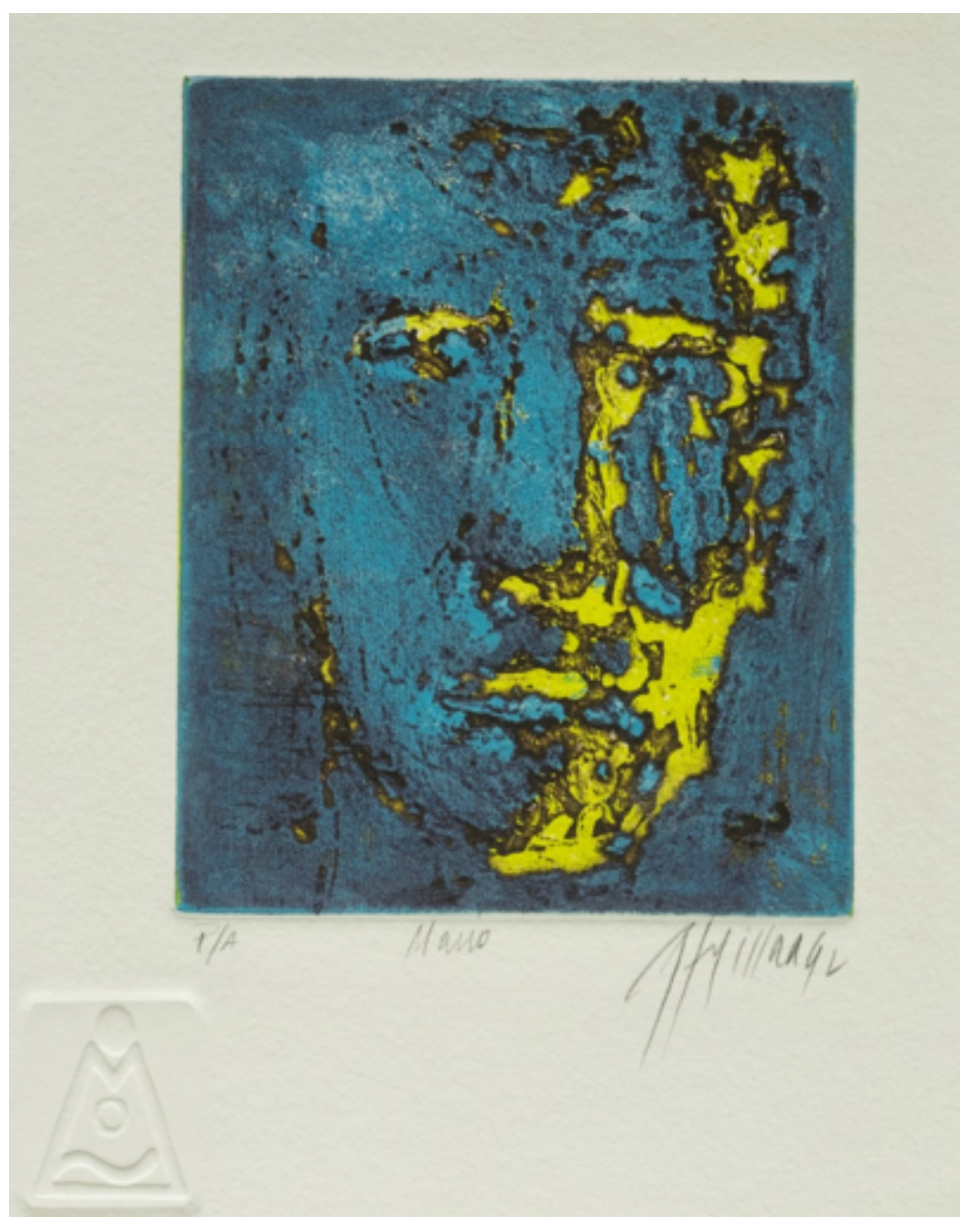

Fuente: Familia de Rudy Espinoza

Como ejemplo del dominio alcanzado con esta técnica tenemos las seis versiones de Mario (Figuras 2, 3, 4 y 5) de 1992, un grabado a modo de políptico en donde logramos ver en cada estampa además de la maestría técnica, los dotes de colorista de su autor.

En las obras de Espinoza, técnica y contenido van de la mano. Desde inicios de la segunda mitad del siglo XX, el reconocido intelectual canadiense Marshall McLuhan afirmó que en los procesos de comunicación utilizados por la sociedad actual (incluido el arte), medio y mensaje funcionan en pareja y no se pueden pensar por separado, ambos se afectan de manera mutua e incluso el mensaje, 
Figuras 4 y 5. Mario (1992)
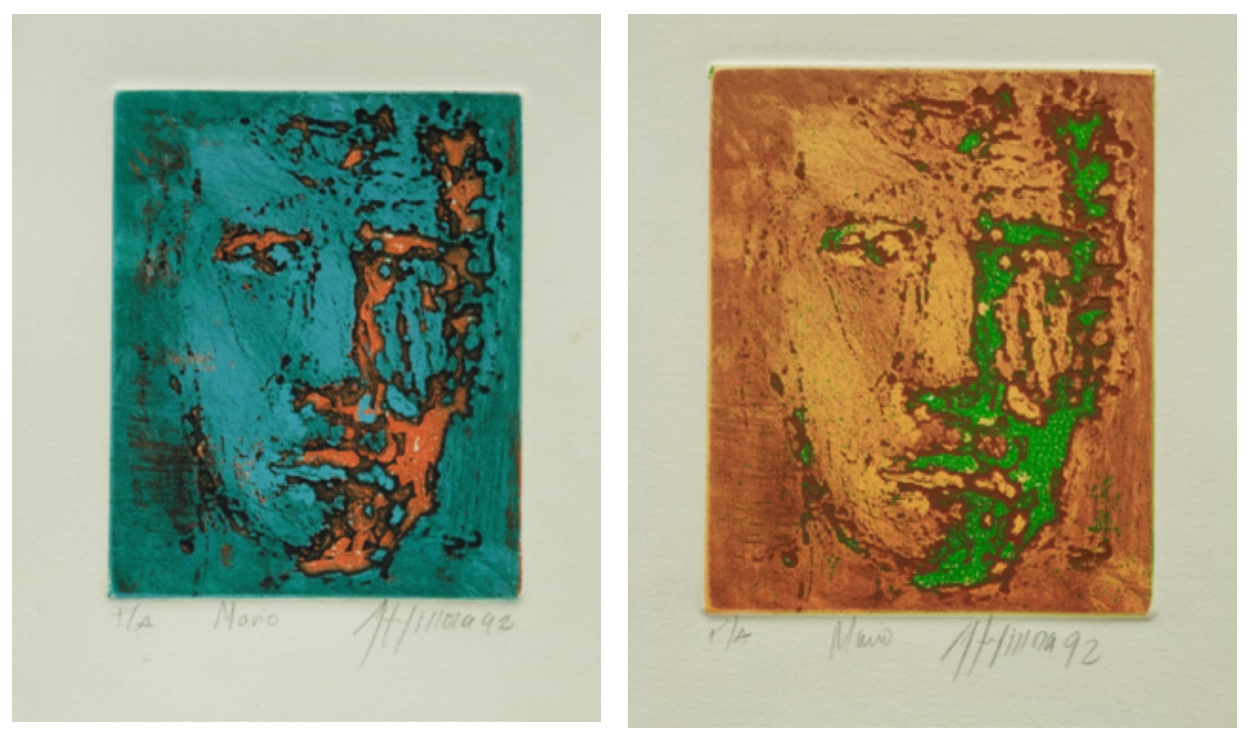

Fuente: Familia de Rudy Espinoza

en algunos casos, estaría cifrado en el medio utilizado para propagarlo, de ahí se desprende su conocida frase: "El medio es el mensaje".

Todos los medios nos vapulean minuciosamente. Son tan penetrantes en sus consecuencias personales, políticas, económicas, estéticas, psicológicas, morales, éticas y sociales, que no dejan parte alguna de nuestra persona intacta, inalterada, sin modificar. El medio es el mensaje. Ninguna comprensión de un cambio social y cultural es posible cuando no se conoce la manera en que los medios funcionan de ambientes. (McLuhan y Fiore, 1997, p. 26)

El dominio magistral de una técnica tan compleja como la inventada por Hayter forma parte de la producción de pensamiento en la labor desarrollada por Espinoza a lo largo de más de cuatro décadas de experiencia. Obra final y proceso son tan importantes en su trabajo creativo, que en sus estampas logramos apreciar por igual: rigurosidad y método, metáfora y poesía, como gesto e improvisación, sin que exista ninguna contradicción en su resultado final.

En la estancia académica y profesional en el taller de grabado de la Universidad de Minnesota, al que él llamó: "un espacio de confluencias", debido a que eran muchos los artistas que se reunían a realizar estudios y pasantías, desarrolló trabajos experimentales y con un gran sentido de la estética, como por ejemplo: Imagen en la capilla (1984) y Escritorio y libertad en papel (1984) (Figura 6) y otros de gran fuerza expresiva como Absorción (1984) (Figura 7), Fatiga (1984) 
Figura 6. Escritorio y libertad en papel (1984)

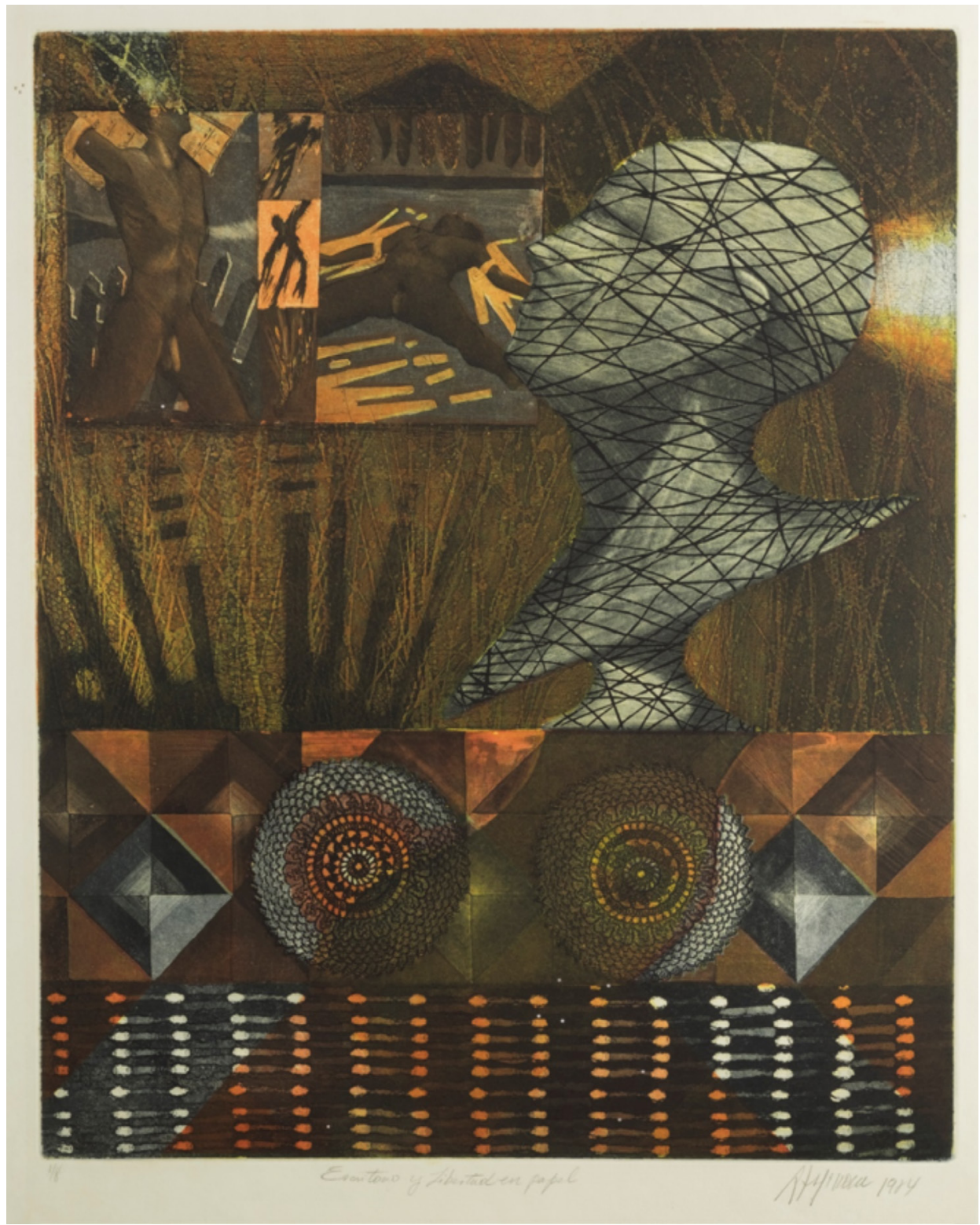

Fuente: Familia de Rudy Espinoza 
Figura 7. Absorción (1984)

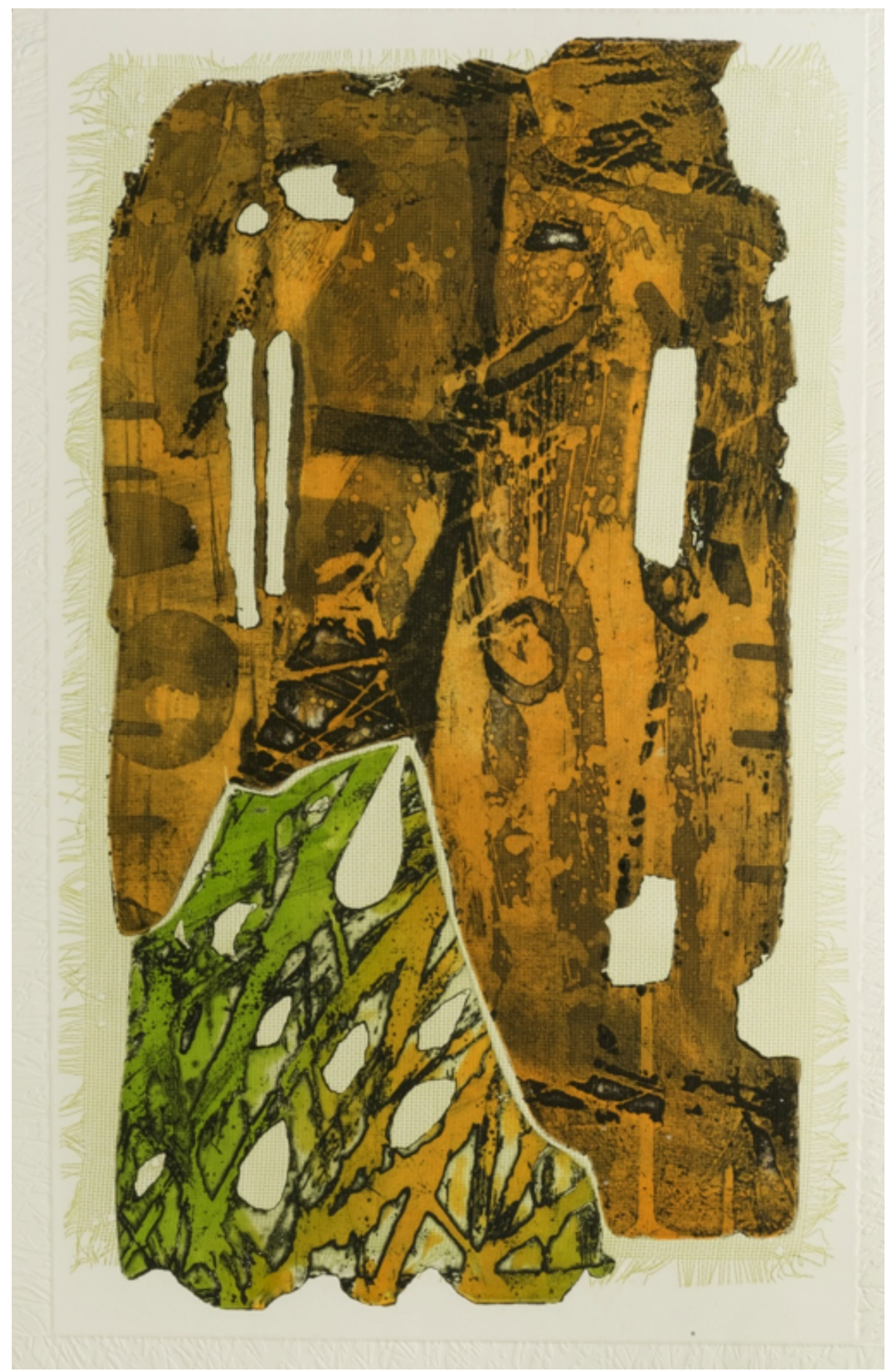

Fuente: Familia de Rudy Espinoza 
y Bajo presión (1984), concebidas estas últimas tres a partir de diferentes placas ya trabajadas y que fueron abandonadas en el taller, las que Espinoza retomó e intervino cortándolas, taladrándolas y sometiéndolas a intensos procesos de quemado, creando con dos o tres de ellas nuevas composiciones con texturas y gestos plásticos bastante intensos.

En su fructífera carrera, Espinoza demostró ser un virtuoso del dibujo, la composición y el uso del color, además de un verdadero maestro de las diferentes técnicas del grabado en metal. Se esmeró en ordenar su proceso creativo mediante el diseño de series temáticas en las que agota sus ideas a partir de conjuntos coherentes de sentido y con una fuerte unidad estética. Entre sus primeras series están las que abordan temas urbanos, trabajados desde la perspectiva de lo cotidiano como escenas del espacio público, entre ellas: La cuesta (1976), El desgajo (1978), Cien varas al sur (1976) e inclusive Patio (1980) y Rutina (1981), así como otros trabajos que reflexionan sobre la concepción del espacio urbano privado o habitacional, en donde apreciamos: El placer de observar (1977), El ladrón de frutas (1977) y bodegones como Fruta con semillas (1981) y Motete (1981).

A lo largo de su carrera, la figura humana y la animalística son temas recurrentes; series como En cautiverio (1986-8) o Cuerpos dulces (1998-2000) son ejemplos rotundos del abordaje de estos motivos. Espinoza recurre al animal como metáfora del ser humano, retrata de formas simbólica gestos culturales como la sexualidad, la violencia, la opresión o el uso excesivo del poder. Con esta temática apreciamos: El pájaro rojo (1990), El año del toro (1994), El toro rojo (1997), El salto (1997) y Cabezas de caballo (2013). Según lo que nos comentan Hernández y Alvarado (2006) el uso del animal en la obra de Espinoza trata problemáticas de lo humano a nivel político, social y existencial. Obras como El hoyo de los locos (2010) es un ejemplo donde se integran armoniosamente tanto de forma compositiva como temática la figuración humana y animal, y en Ánimos alterados (2010) las actitudes animales son un reflejo o metáfora de las humanas.

Entre las distinciones obtenidas por su trabajo sobresalen el Primer Premio en Certamen de Grabado de 1997. Anteriormente, en 1991, obtuvo el Segundo Lugar del Certamen Nacional de Grabado convocado por el Museo de Arte Costarricense (MAC) y el Segundo Lugar del Certamen Nacional de Dibujo convocado por la Caja Costarricense de Seguro Social. Consigue medalla de oro en el Salón Nacional de Dibujo convocado por el MAC de 1987, mismo año que se le otorga la medalla de oro en el Salón Nacional de Grabado, y en 1981 había sido merecedor del Premio Nacional Aquileo J. Echeverría en Grabado. Con una trayectoria de más de 40 años dedicado al grabado, dibujo y pintura, llegó a realizar más de una centena de exhibiciones colectivas e individuales dentro y fuera del país. 
La figura humana está presente de forma directa o indirecta en la mayoría de sus obras. El cuerpo como espacio de batalla y escenario de valores sociales está presente en obras como: Cuerpo azul (1999), Tu cuerpo (1998) у Cuerpo seducido (2000). También contamos con Torso (1998) y Equilibrio (2000) como claros ejemplos donde a partir del dibujo se explora el cuerpo humano como estética y belleza. En El eterno interno (2010) y Paranoia con Van Gogh (2009) se explora la humanidad en su dimensión más existencial.

También tenemos en Espinoza un artista que fluctúa de manera natural, limpia y sin prejuicios entre la figuración y la abstracción. En algunos trabajos predomina una línea pulcra de proporciones correctas, en otros es el trazo gestual y energético el que tiene más presencia. En paisajes como Lagunilla (1981) y Paisaje del norte (1981) vemos ejemplos de una fina figuración y en Paisaje \#19 (1981) tenemos una composición o un estado intermedio, mientras que en obras como Piros (1979), Por la montaña en el cerro (1981) o Maleza (1981) la abstracción y el gesto es lo que predomina. Algunas de estas obras se componen de dos matrices o placas que se integran para formar una sola composición. El acento estético con el que Espinoza trabajó estas piezas denotan estar resueltos por un pintor, en donde el color y la mancha son parte importante de la composición, sin embargo, también apreciamos la mente de un grabador detrás de estos proyectos, porque en el uso de la textura e incluso el recurso del intaglio y la impresión en blanco forman parte indiscutible de la composición; de esta forma, nuevamente vemos como en los trabajos de Espinoza, forma y contenido se refuerzan mutuamente.

En obras como Después del tsunami (2012) (Figura 8) lo que domina la composición es el gesto expresionista y dramático, sin descuidar -claro está- el dibujo con vocación figurativa, fundiéndose las dos tendencias en una obra de extraordinaria factura técnica y conceptual. Otras series o conjuntos como Marenostrum (200013), Las cuatro estaciones (1990) o Pecado y redención (2006) tratan temas más puntuales como la fauna marina, las estaciones climáticas y la lucha del bien contra el mal.

\section{Los últimos diez años del maestro}

Luego de su jubilación como docente universitario, Espinoza concibió un proyecto de docencia independiente donde continua con su labor de formador de grabadores y puede brindar, de forma desinteresada, todo el conocimiento atesorado por más de 40 años dedicado al perfeccionamiento de las técnicas de estampación de imágenes. Este es el origen del "Taller Nacional de Grabado", un espacio alternativo para la enseñanza y aprendizaje de las diferentes técnicas del grabado en todos sus aspectos. Desde su fundación en el 2008, el Taller se instaló en la Escuela Casa del Artista Olga Espinach Fernández del Museo de Arte Costarricense 
Figura 8. Después del tsunami (2012)

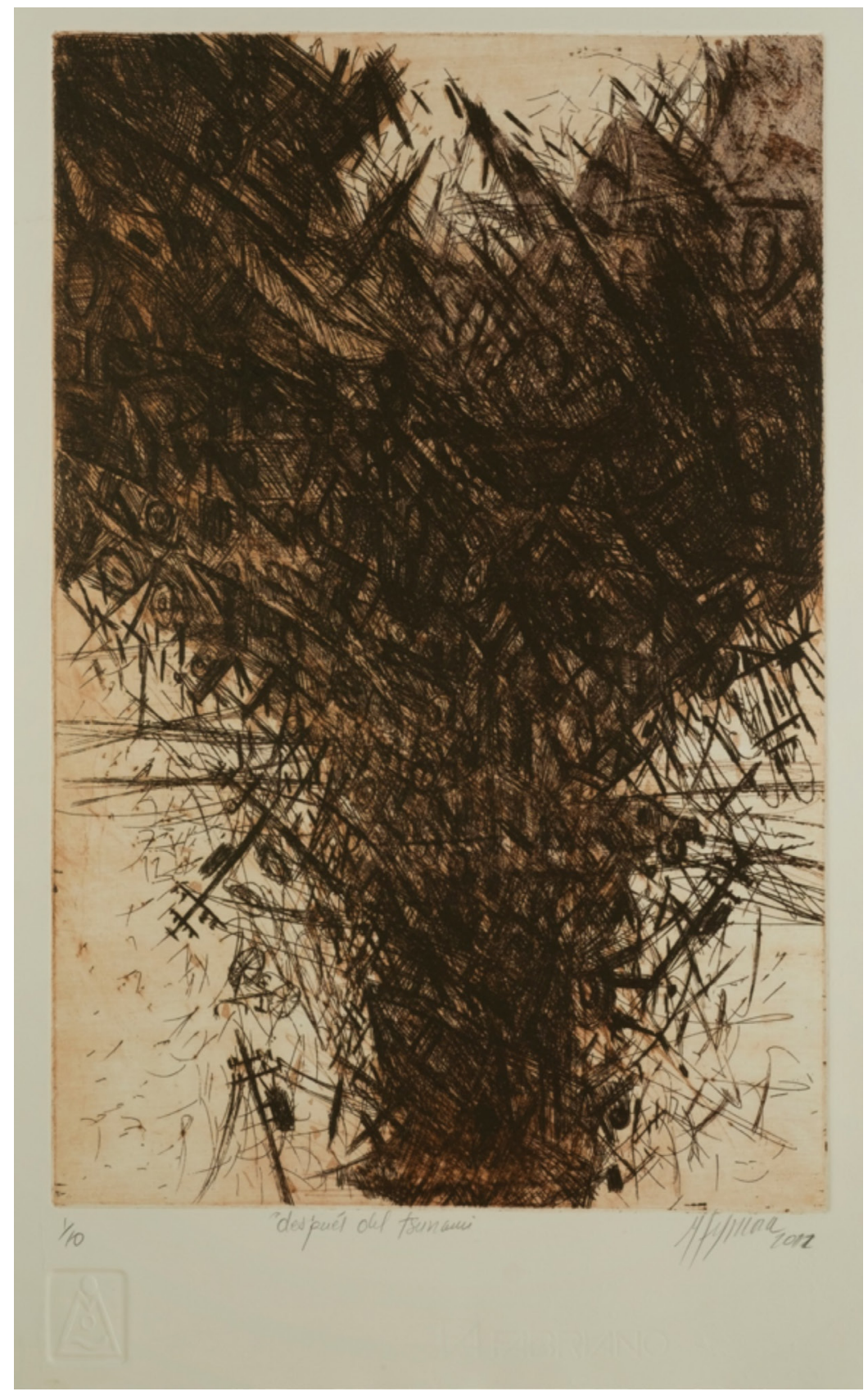

Fuente: Familia de Rudy Espinoza 
(MAC) y se ha vuelto parte integral de la institución. Durante los últimos diez años de vida Espinoza, quien falleció el pasado 15 de enero del 2018, se desempeñó como coordinador y profesor ad-honorem de este espacio de enseñanza.

Figura 9. Rudy Espinoza en su estudio a finales del 2007 revisando uno de sus últimos trabajos.

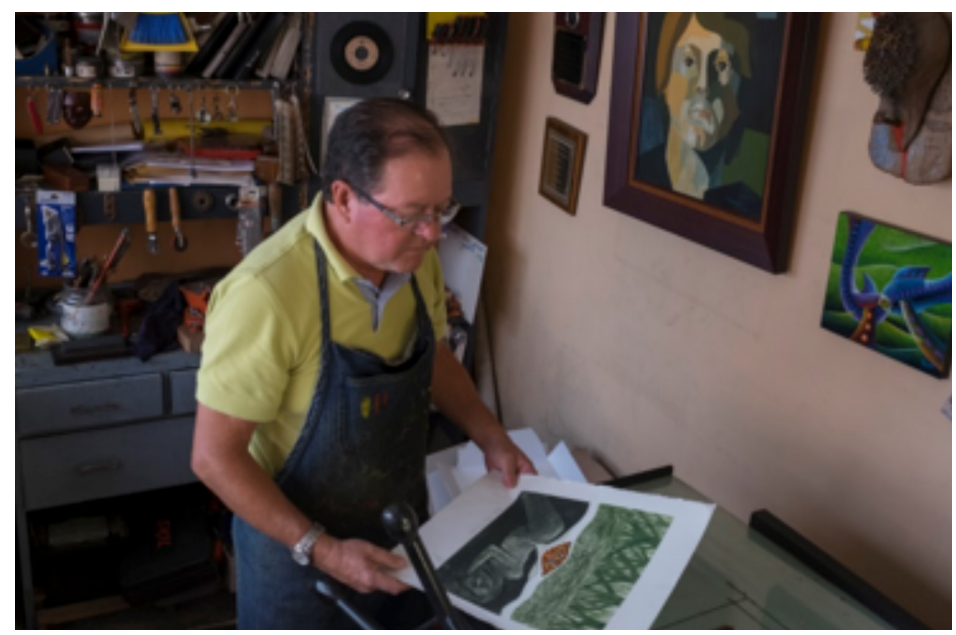

Fuente: Familia de Rudy Espinoza

Durante sus clases en el Taller de la ECA, además de fomentar el trabajo del grabado en metal, Espinoza tuvo la oportunidad de crear obras en compañía de sus alumnos, todo en un ambiente de camaradería y compañerismo. Profesionalismo, pasión, dedicación, honestidad, humildad y generosidad sin límites, son algunos de los muchos valores que aquellos que fuimos sus estudiantes, amigos o colegas asociamos a Rudy Espinoza; su trabajo plástico y vocación de maestro son la impronta más importante que deja en la historia del arte costarricense, una huella tan profunda como la que se aprecia en una placa de grabado luego de más de cuatro décadas de quemados sucesivos. 
Figura 10. Madre Natura: Manglar (2017)

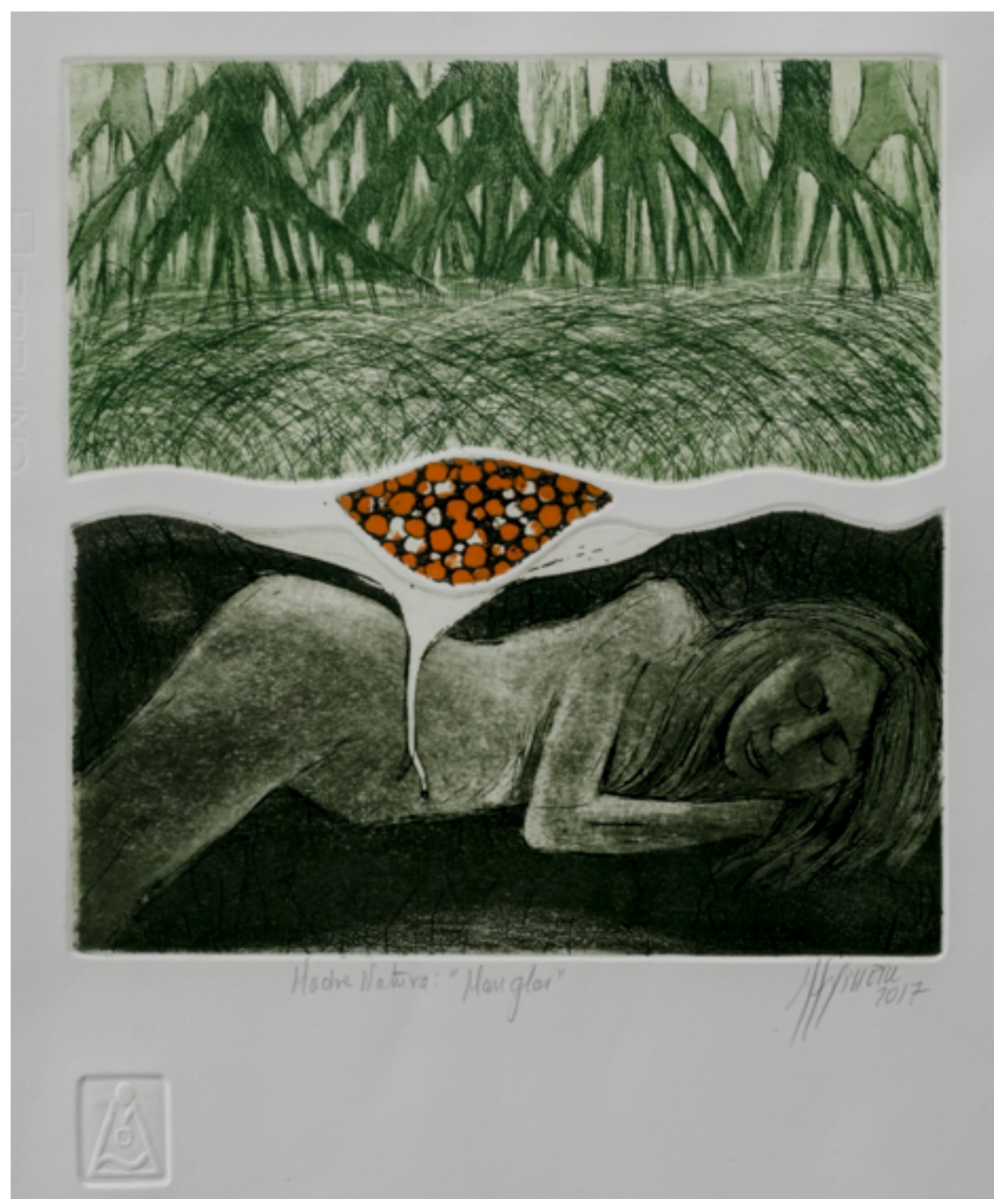

Fuente: Familia de Rudy Espinoza 
Esteban Alfredo Calvo Campos

Las huellas de un maestro: Breve comentario a la vida y obra de Rudy Espinoza (1953-2018)

Figura 11. Madre Natura: La proveedora (2017)

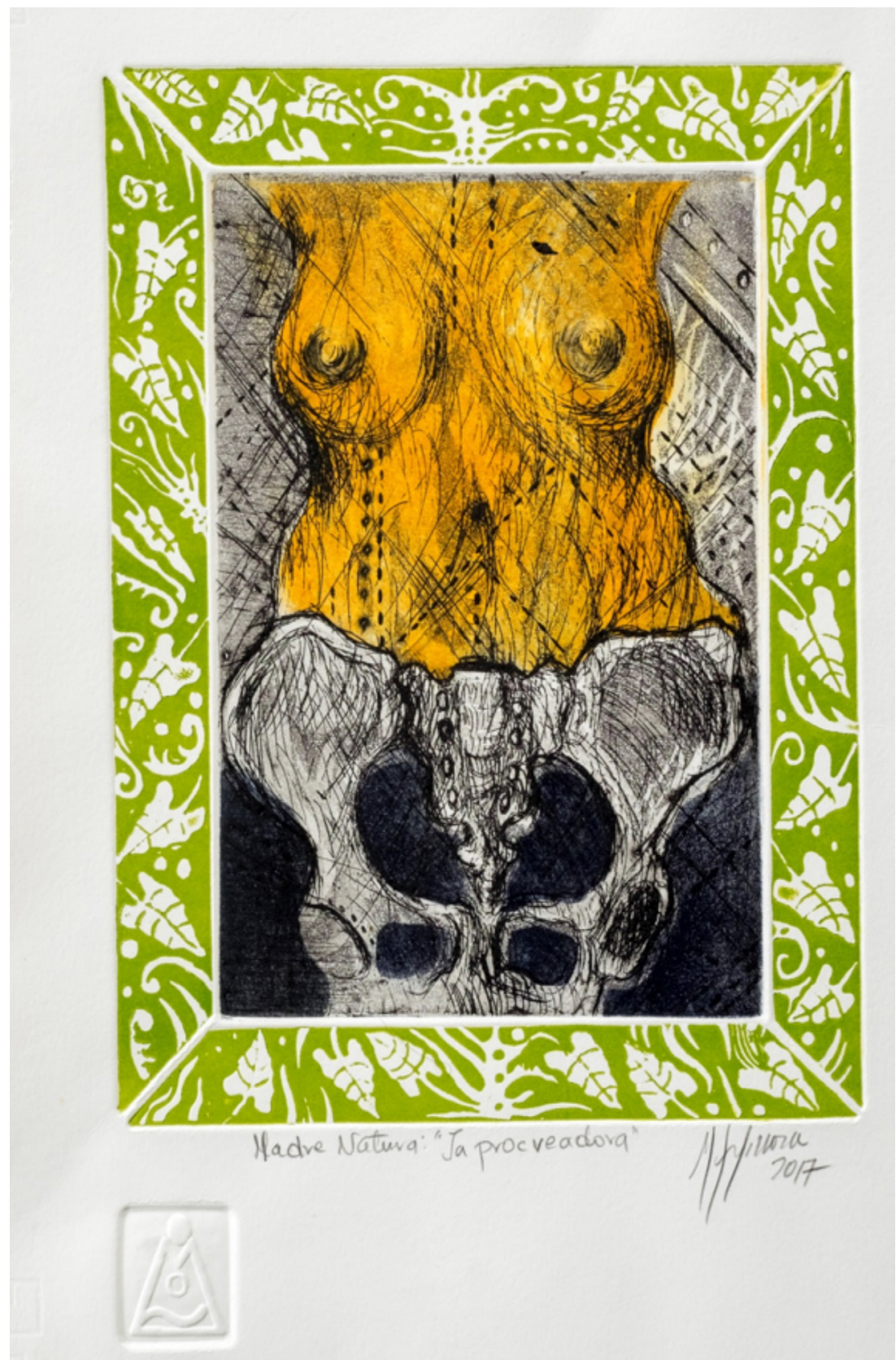

Fuente: Familia de Rudy Espinoza 


\section{Referencias:}

Alvarado, I. (1992) Proyecto Multinacional Regional de Estudios Especializados en Artes Graficas (CREAGRAF). (Tesis de Licenciatura, Universidad de Costa Rica).

Durán, S. (2014) Una visión más allá de la obra gráfica, a través de los ojos de Rudy Espinoza. (Trabajo final de graduación), Maestría Profesional en $\mathrm{Hu}-$ manidades. Universidad Latina de Costa Rica, Costa Rica.

Hayter, S.W. (1981) New ways of gravure. New York: Watson-Guptill.

Hernández, E. y Alvarado, I. (2006) La animalística en el arte costarricense. San José: Fundación Museos del Banco Central.

McLuhan, M. y Fiore, Q. (1997) El medio es el mensaje. Un inventario de efectos. Barcelona: Paidós. 